\title{
Effect of Linagliptin and Voglibose on metabolic profile in patients with Type 2 Diabetes: a randomized, double-blind, placebo-controlled trial
}

\author{
Girish Parthan ${ }^{1}$, Shobhit Bhansali ${ }^{1}$, Anura V. Kurpad ${ }^{2}$, Rama Walia ${ }^{1}$, Kishor Bhat ${ }^{2}$ and Anil Bhansali ${ }^{1 *}$
}

\begin{abstract}
Background: Dipeptidyl peptidase 4 (DPP4) inhibitors improve glycemic control by promoting GLP1-mediated glucose-dependent insulin secretion and suppression of glucagon. Sitagliptin and vildagliptin have been shown to improve insulin sensitivity in patients with type 2 diabetes mellitus (T2DM). However, these patients had uncontrolled blood glucose at inclusion; therefore, the improvement in insulin sensitivity observed in these studies could be attributed to the drug per se and/or reduction in glucotoxicity. This study examines the effect of linagliptin on insulin sensitivity and $\beta$-cell function in patients with well-controlled T2DM.

Methods: Thirty patients with T2DM of duration $\leq 5$ years, and having $\mathrm{HbA} 1 \mathrm{c}<7.5 \%$ were randomized to receive linagliptin, voglibose or placebo ( $n=10$ each), and were followed up for 6 months. Insulin sensitivity was assessed by hyperinsulinemic-euglycemic clamp, and insulin secretory response was measured by basal $\left(\mathrm{M}_{0}\right)$ and postprandial $\left(M_{1}\right) \beta$-cell function, and area under curve (AUC) for C-peptide during mixed meal tolerance test.

Results: The median HbA1c of the study subjects at inclusion was $6.9 \%$ and there was no significant difference among the groups in terms of age, duration of diabetes, body mass index (BMI), HbA1C, insulin sensitivity, AUC of C-peptide and $M_{0}$ and $M_{1}$ at baseline. At the end of the study, there was a modest reduction in HbA1c $(-0.2 \%)$ in the linagliptin group, and a significant decrease $(-0.8 \%)$ in the voglibose group, as compared to placebo ( $p=0.038)$. However, there were no significant differences in insulin sensitivity, $M_{0}$ and $M_{1}$ and AUC of C-peptide, within, or among the groups.
\end{abstract}

Conclusion: Linagliptin modestly improves glycemic profile in patients with well controlled T2DM; however, it may not have an effect on insulin sensitivity in these patients.

Trial registration: Retrospectively Registered in Clinicaltrials.gov (ID number, NCT02097342). Registered: March 27, 2014.

Keywords: T2DM, $\beta$-cell function, insulin sensitivity, linagliptin, voglibose

\section{Background}

The prevalence of diabetes is increasing worldwide and is fast expanding from developed countries to developing countries. As per an estimate by the International Diabetes Federation, 414 million adults were affected with diabetes in 2015 , and this number is likely to swell to 642 million by 2040 [1].

\footnotetext{
* Correspondence: anilbhansaliendocrine@gmail.com

${ }^{1}$ Department of Endocrinology, Post Graduate Institute of Medical Education and Research, Sector- 12, Chandigarh PIN Code-160012, India

Full list of author information is available at the end of the article
}

Type 2 diabetes mellitus (T2DM) is characterized by two cardinal defects; insulin resistance and insulin deficiency. A plethora of drugs are available for the treatment of T2DM; incretin-based therapies such as dipeptidyl peptidase-4(DPP-4) inhibitors and glucagon like peptide-1(GLP-1) receptor agonists are among the recent additions to the therapeutic armamentarium in T2DM [2].

DPP-4 inhibitors are orally acting drugs that have efficacy similar to sulfonylureas, but without the risk of hypoglycemia or weight gain. DPP-4 inhibitors are

(C) The Author(s). 2018 Open Access This article is distributed under the terms of the Creative Commons Attribution 4.0 International License (http://creativecommons.org/licenses/by/4.0/), which permits unrestricted use, distribution, and 
commonly used as second-line drugs in the management of T2DM, although they have been found to be useful as monotherapy, as well [3]. These drugs enhance the effect of endogenous GLP-1 by preventing its degradation, and this results in augmentation of glucose-dependent insulin secretion and suppression of glucagon, thereby reducing blood glucose. DPP-4 inhibitors are also known to improve pancreatic $\beta$-cell function [4-7]. In addition, DPP-4 has also been shown to be an adipokine, which impairs insulin sensitivity in an autocrine and paracrine fashion [8]; hence, DPP-4 inhibition may improve insulin sensitivity. Previously, few studies have reported an improvement in insulin sensitivity with DPP-4 inhibitors, sitagliptin and vildagliptin $[9,10]$. However, these studies included patients with uncontrolled diabetes $(\mathrm{HbA} 1 \mathrm{c}>8 \%)$ and one of the potential reasons for the improvement in insulin sensitivity observed in these studies could be due to reduction in glucotoxicity, rather than the direct effect of these drugs on peripheral utilization of glucose. Recently, linagliptin has been shown to improve insulin sensitivity in diet-induced obese mice [11].

There are various methods to assess the insulin sensitivity like insulin tolerance test, frequently sampled intravenous glucose tolerance test, quantitative insulin sensitivity check index (QUICKI), mixed meal tolerance test, Matsuda index and homeostasis model assessment-estimated insulin resistance (HOMA-IR) [12]. However, the "gold standard" for the assessment of insulin resistance is hyperinsulinemic euglycemic clamp study [13]. Till date, no study has evaluated the effect of linagliptin on insulin sensitivity in humans by using hyperinsulinemic-euglycemic clamp study. This is a pilot study which aimed to evaluate the effect of linagliptin on insulin sensitivity and $\beta$-cell function by using hyperinsulinemic euglycemic clamp and mixed meal tolerance test, respectively, in patients with well controlled T2DM.

\section{Methods \\ Study design}

Patients with T2DM, aged between 30 and 65 years, with duration of diabetes $<5$ years, and were on metformin $2 \mathrm{~g} /$ day for at least 6 weeks, with HbA1c $<7.5 \%(<58.0 \mathrm{mmol} / \mathrm{mol})$ were included in the study. Patients with history of ketoacidosis, abnormal liver function tests (plasma aminotransferase elevations of more than 3 times upper limit of normal), renal failure (serum creatinine more than $1.5 \mathrm{mg} / \mathrm{dL}$ ), macular edema, coronary artery disease or heart failure, cerebrovascular disease, and those requiring insulin were excluded. Pregnant and lactating women, and those who received any DPP-4 inhibitors in the last 3 months were also excluded. All patients were educated about their disease and were advised life-style modifications. Informed consent was obtained from the study subjects. Institute Ethics Committee approved the study, and the trial was registered at Clinicaltrials.gov (ID number, NCT02097342). Patients were allocated into three groups by random allocation software and received linagliptin $5 \mathrm{mg}$ once daily (OD), placebo OD or voglibose (0.2 $\mathrm{mg}$ three times daily), and were followed up for 6 months. Voglibose was used as an active comparator to evaluate the effects of linagliptin on insulin sensitivity independent of alterations in HbA1c. Both patients and physicians were blinded to treatment, but the active comparator group of voglibose was open-labeled, as it was given three times a day.

\section{Baseline evaluation}

Baseline evaluation included clinical examination, and biochemical assessment of glycemic control and evaluation for micro- and macrovascular complications.

Fasting plasma glucose (FPG), C-peptide, homeostasis model assessment estimated insulin resistance index (HOMA-IR), homeostasis model assessment $\beta$-cell function index (HOMA- $\beta$ ) and hyperinsulinemic euglycemic clamp study were performed at baseline. A mixed meal tolerance study was also done at baseline, after a week of HEC. Laboratory investigations were performed between 8 and 9 am after an overnight fast, and venous blood samples were collected in ethylenediaminetetraacetic acid (EDTA) vacutainer. Glycated hemoglobin (HbA1c) was estimated by an automated high-performance liquid chromatography (HPLC)-based system using ion-exchange cartridge (D-10, Bio-Rad Laboratories, Inc., Hercules, CA, USA). C-peptide estimation was done by electrochemiluminiscence immunoassay (ECLIA) (Elecsys 2010, Roche Diagnostics $\mathrm{GmbH}$, Mannheim, Germany).

\section{Estimation of homeostatic model assessment}

The new version of the homeostatic model assessment of insulin resistance (HOMA-IR) and $\beta$ cell function (HOMA- $\beta$ ) was estimated as per the standard formulae $[14,15]$.

\section{Hyperinsulinemic-Euglycemic clamp study}

Hyperinsulinemic-euglycemic clamp study was performed in all subjects to assess in-vivo insulin sensitivity. Subjects were requested to refrain from vigorous exercise, and reported at $0630 \mathrm{~h}$ after an overnight fast of $10 \mathrm{~h}$. An intravenous catheter was inserted into the antecubital vein for infusion of insulin and $25 \%$ dextrose solutions, while another catheter was inserted in an anti-flow direction into the dorsal vein of the contralateral hand for arterialized blood sampling. An insulin infusate of $300 \mathrm{mU} / \mathrm{ml}$ was prepared from regular human insulin (Eli Lilly \& Co. Gurugram, India) in $100 \mathrm{ml}$ isotonic saline and $4 \mathrm{ml}$ of subject's blood. Insulin was infused intravenously based 
on the surface area at a constant rate $\left(40 \mathrm{mU} / \mathrm{m}^{2} / \mathrm{min}\right)$ to raise the plasma insulin concentration to about $100 \mu \mathrm{U} / \mathrm{mL}$. The glucose infusion rate was adjusted to maintain a steady state of $4.9 \mathrm{mmol} / \mathrm{L}$. Blood samples for glucose and insulin were collected every 5 and $20 \mathrm{~min}$, respectively. Plasma glucose was analysed by glucose oxidase method on a bedside glucose analyzer (GM9D, Analox instruments, London, UK). $M$ value, a measure of glucose utilization, and $M / I$, an index of insulin sensitivity were calculated over 40 to 120 min of the clamp study [13].

\section{Mixed meal tolerance test}

The mixed meal at a dose of $10 \mathrm{Kcal} / \mathrm{Kg}$, (Ensure, Abbott Nutrition, Abbott Laboratories, India) was dissolved in $500 \mathrm{~mL}$ of water and was consumed within $10 \mathrm{~min}$. Medications taken by the subject in the morning were administered 20 min prior to the start of the test meal. C-peptide concentrations were estimated at $0,30,60,90$, 120, 150 and $180 \mathrm{~min}$. Total area under curve (AUC) for C-peptide from pre-meal to $180 \mathrm{~min}$ was calculated.

\section{Insulin secretion model}

Basal $\beta$-cell function (BBCF) and postprandial $\beta$-cell function (PBCF) were assessed from glucose and C-peptide time-concentration profiles during the MMTT using an insulin secretion model [16]. $\mathrm{M}_{0}$ is an index of the BBCF and represents the ability of fasting plasma glucose to stimulate the $\beta$-cell. $\mathrm{M}_{\mathrm{I}}$ is an index of $\mathrm{PBCF}$ and represents the ability of postprandial glucose to step up $\beta$-cell secretion. It equals the increment in insulin secretion in response to a unit increment in plasma glucose concentration.

\section{Follow-up}

All patients were followed up for a period of 6 months. Lifestyle modification advice was reinforced during each visit to all the patients. All concomitant medications were continued throughout the study period without any dose modifications. Biochemical parameters and hyperinsulinemic-euglycemic clamp study and mixed meal tolerance test were repeated after 6 months.

\section{Statistical analysis}

All data are expressed as median and interquartile range. Baseline and post-treatment data within the groups were compared using Wilcoxon's signed rank test. The data between the groups were analyzed using the Kruskal Wallis test followed by Mann-Whitney test for two groups ( $P$ value corrected using Bonferroni procedure). A $p$ value $<0.05$ was considered significant. The statistical analysis was carried out using the SPSS version 22 for Windows (SPSS Inc., Chicago, USA).

\section{Results}

Study subjects

Twenty-six out of thirty patients completed the study; 10 in the linagliptin group, 9 in the voglibose group and 7 in the placebo group (Fig. 1). One patient in placebo and voglibose group was excluded due to gastrointestinal side-effects, while two patients withdrew their consent for study in the placebo group. The baseline clinical and biochemical characteristics of the three groups were similar (Table 1).

\section{Efficacy}

The median HbA1c of the study subjects at baseline was $6.9 \%$ and at the end of study it reduced to $6.6 \%$. After 6 months of linagliptin and voglibose therapy reduced the HbA1c from 6.8 to $6.6 \%(p=0.474)$ and 7.0 to $6.6 \%$; $p=0.015$ ), respectively, whereas in the control group, HbA1c did not change (Table 2, Fig. 2).

Patients treated with linagliptin and voglibose showed a decrease in FPG levels, while FPG increased in the control group. HOMA-IR, HOMA- $\beta$, glucose disposal rate, insulin sensitivity, $M_{0}$ and $M_{1}$ response and AUC for C-peptide did not change significantly in any of the study groups after 6 months (Table 2, Figs. 3 and 4).

\section{Comparison among the groups}

Among the groups, there were no significant alterations in clinical parameters at 6 months. HbA1c significantly decreased in the voglibose group as compared to the control group $(p=0.038)$. On mixed meal tolerance test and HEC, there were no significant differences between $\Delta \mathrm{M}_{0}, \Delta \mathrm{M}_{1}, \Delta \mathrm{AUC}$ of $\mathrm{C}$-peptide, and $\Delta$ glucose disposal rate and $\Delta$ insulin sensitivity, respectively (Table 3 ).

\section{Discussion}

Our study demonstrated a modest reduction in HbA1c and insignificant alterations in insulin sensitivity indices in patients with well controlled T2DM who were treated with linagliptin. Our study is a pioneer to demonstrate the effect of linagliptin on insulin sensitivity indices, independent of glucotoxicity, as opposed to the previous studies with DPP 4 inhibitors. In addition, this is the first study in the English literature to evaluate the effect of voglibose on insulin sensitivity using HEC.

In the linagliptin group, HbA1c decreased from 6.8 to 6.6\%; however, the difference was not statistically significant. The HbA1c reduction with linagliptin in our study was lower than previously reported, and this may be because of lower HbA1c at baseline (6.8\%) [17-19]. It is well known that with any anti-diabetic medication, subjects with higher baseline $\mathrm{HbA1c}$ exhibit greater reduction in HbA1c, as compared to those with near-normal glycemia. Moreover, the effect of DPP-4 inhibitors is glucose-dependent; hence, in subjects with 


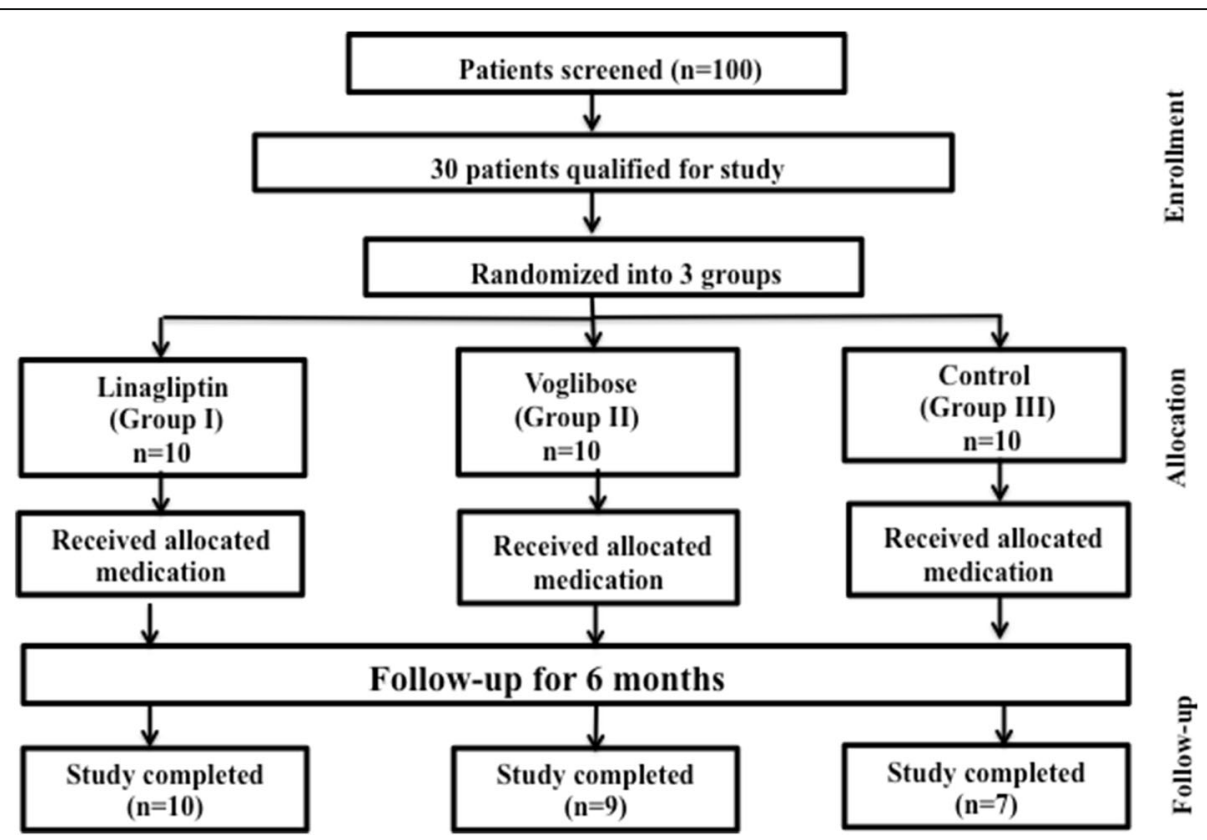

Fig. 1 Schema of the study

near normal HbA1c, their efficacy may be further reduced [20]. There was a significant reduction in HbA1c in the voglibose group at the end of 6 months (from 7.0 to $6.6 \%)$. The higher $\mathrm{HbA} 1 \mathrm{c}$ reduction observed in our study with voglibose could be due to the dietary habits of the study population, who consume a predominantly carbohydrate-rich diet.
Parameters of insulin resistance assessed by HOMA-IR, glucose disposal rate and insulin sensitivity did not show significant alterations in any of the groups. Improvement in insulin sensitivity with any anti-diabetic agent could be due to its direct insulin sensitizing effect on peripheral tissues or due to reduction in glucotoxicity, or both. Previously, Derosa et al. has shown that both sitagliptin and

Table 1 Baseline clinical and biochemical parameters of the study groups

\begin{tabular}{|c|c|c|c|c|}
\hline Parameters & $\begin{array}{l}\text { Linagliptin Group } \\
(n=10)\end{array}$ & $\begin{array}{l}\text { Voglibose Group } \\
(n=9)\end{array}$ & $\begin{array}{l}\text { Control Group } \\
(n=7)\end{array}$ & $P$-value \\
\hline Age (years) & $49.5(41.5-55.5)$ & $50.0(45.0-54.0)$ & $54.0(48.5-59.5)$ & 0.438 \\
\hline Sex (M:F) & $5: 5$ & $7: 2$ & $5: 2$ & \\
\hline Duration of diabetes (years) & $2.5(1.0-3.0)$ & 2.5 (0.8 to 3.0$)$ & $2.0(0.8-2.8)$ & 0.813 \\
\hline Weight (Kg) & $75.3(69.2-85.3)$ & $60.7(55.4-71.5)$ & $74.0(58.7-84.4)$ & 0.071 \\
\hline BMI $\left(\mathrm{Kg} / \mathrm{m}^{2}\right)$ & $25.5(23.6-31.1)$ & $25.9(23.8-26.6)$ & $26.4(23.8-30.5)$ & 0.834 \\
\hline $\mathrm{HbA1c}(\%)$ & $6.8(6.4-7.1)$ & $7.0(6.8-7.4)$ & $7.0(6.8-7.1)$ & 0.350 \\
\hline Fasting Plasma Glucose (mmol/L) & $6.5(5.9-7.3)$ & $6.9(6.2-7.4)$ & $6.2(6.1-6.6)$ & 0.287 \\
\hline AUC C-peptide (nmol/L) & $473.3(376.9-567.8)$ & $421.2(40.9 .8-526.9)$ & $595.6(460.5-623.8)$ & 0.223 \\
\hline $\mathrm{M}_{0} \times 10^{-8}(1 / \mathrm{min})$ & $-0.4(-2.6-0.8)$ & $-0.5(-2.8-1.2)$ & $-2.6(-5.9-1.2)$ & 0.834 \\
\hline$M_{1} \times 10^{-8}(1 / \mathrm{min})$ & $6.4(4.5-8.7)$ & $5.7(3.6-7.6)$ & $7.7(5.5-10.6)$ & 0.319 \\
\hline Glucose disposal rate (mg/Kg min) & $2.7(2.0-5.5)$ & $3.2(2.6-3.5)$ & $2.2(1.8-3.0)$ & 0.297 \\
\hline Insulin sensitivity $(\mathrm{mg} /(\mathrm{Kgmin}) / \mu \mathrm{U} / \mathrm{mL})$ & $4.4(2.5-8.0)$ & $5.3(3.6-6.7)$ & $3.2(2.3-5.1)$ & 0.315 \\
\hline HOMA-IR & $2.0(1.9-2.3)$ & $1.6(1.3-2.0)$ & $1.9(1.6-2.1)$ & 0.261 \\
\hline HOMA-ß (\%) & $84.1(75.1-95.9)$ & $65.0(52.2-85.7)$ & $92.5(82.6-102.1)$ & 0.067 \\
\hline
\end{tabular}

All values are expressed as median and interquartile range (1st IQR - 3rd IQR)

AUC Area under curve, $M_{O}$ Basal $\beta$-cell function, $M_{1}$ postprandial $\beta$-cell function, HOMA-IR Homeostatic model assessment of insulin resistance, and $H O M A-\beta$ Homeostatic model assessment of $\beta$ cell function 


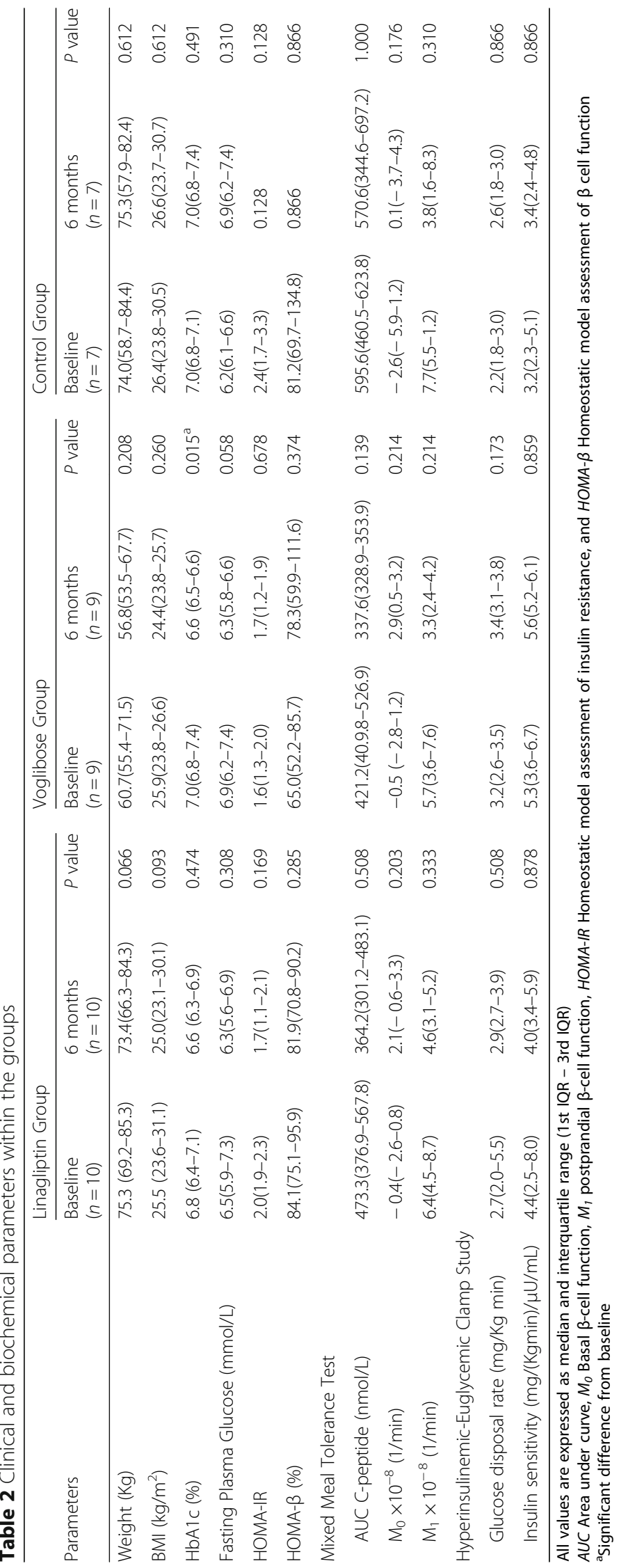




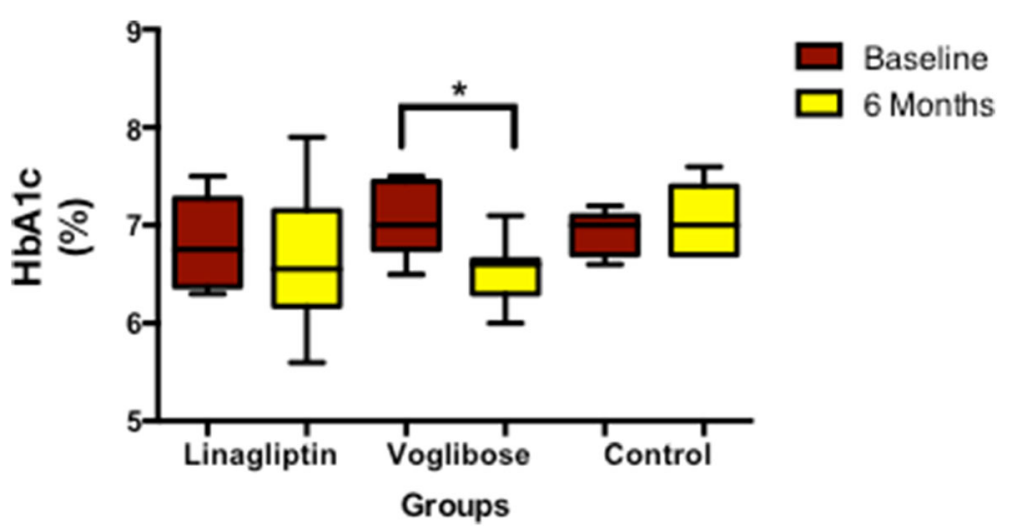

Fig. 2 Change in HbA1c in the study groups. * Means significant difference from baseline

vildagliptin improved insulin sensitivity in patients with T2DM. $[9,10]$. However, the impact of reduction of glucotoxicity on improvement in insulin sensitivity could not be ruled out in these studies, as HbA1c reduced from 8.1 to $6.7 \%$ and 8.1 to $6.9 \%$, with the use of sitagliptin and vildagliptin, respectively. In the present study, we recruited patients with well controlled diabetes to ameliorate the effect of glucotoxicity on insulin sensitivity. There was no significant effect of linagliptin on indices of insulin sensitivity as assessed by HEC. Moreover, the significant reduction in $\mathrm{HbAlc}$ observed in the voglibose group also did not translate into improvement in insulin sensitivity indicating that further reduction in glucotoxicity $(<7 \%)$ may not have a considerable influence on insulin sensitivity.

In the present study, we did not observe any significant alterations in $\beta$-cell function indices among participants in any of the groups. This is similar to the results of the study by Retankaran et al., where subjects with HbA1c $7.8 \pm 0.8 \%$ received intensive insulin therapy for
4-8 weeks and then were randomized to receive either placebo or sitagliptin, with a baseline HbA1c of 6.1 and $6.2 \%$, respectively. Sitagliptin did not demonstrate any improvement in $\beta$-cell function at the end of the study [21]. As the effect of DPP-4 inhibitors is glucose-dependent, it is quite possible that these drugs may not exert significant beneficial effect on $\beta$-cell function in subjects with well-controlled diabetes. On the contrary, a study by Azuma et al., showed that vildagliptin significantly improved both $\beta$-cell function and insulin sensitivity in subjects with a baseline HbA1c 7.1\% [22]. This raises the possibility that improvement in insulin sensitivity seen with vildagliptin in those with relatively well-controlled diabetes may be a drug-specific effect, rather than a class effect of DPP 4 inhibitors [22].

The strengths of our study include the presence of a placebo arm, active comparator as voglibose and the use of hyperinsulinemic-euglycemic clamp technique to assess insulin sensitivity. Voglibose was chosen as an active comparator because of its unique mechanism of action,

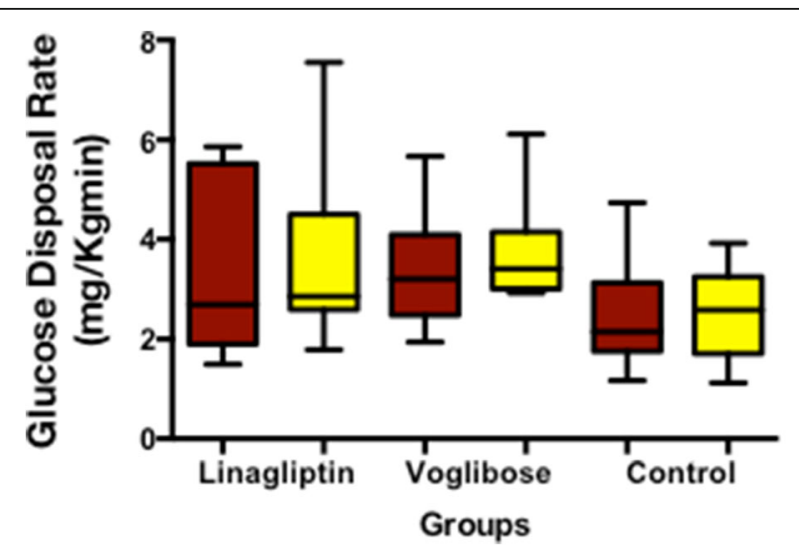

Fig. 3 Change in glucose disposal rate among the study groups 


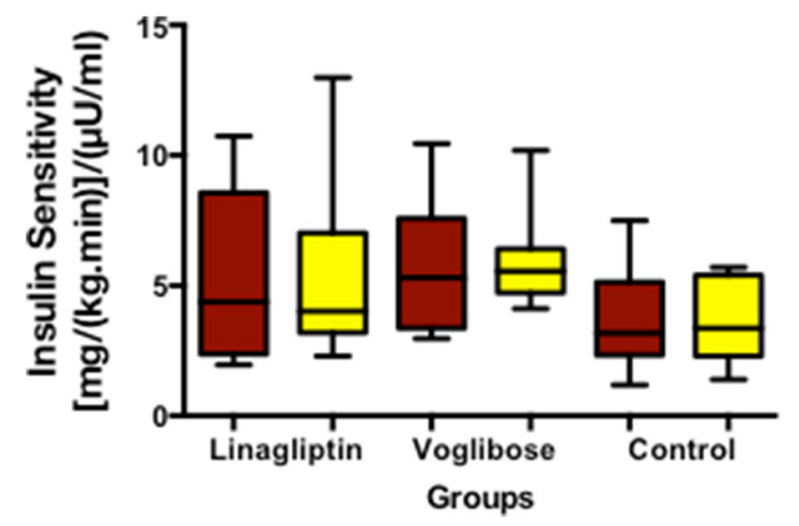

Fig. 4 Change in insulin sensitivity among the study groups

which is insulin-independent, and is not expected to alter insulin sensitivity directly.

There are several limitations in our study. Most importantly, our sample size was small and this prevents us from drawing any meaningful conclusion about the effect of linagliptin on insulin sensitivity. In addition, the duration of study was only 6 months. Since this was a pilot study, we did not calculate the sample size and included 30 patients. Previous studies of DPP 4 inhibitors on insulin sensitivity included larger number of patients and had a follow up of 1 year [9, 10]. However, this was a pilot study to evaluate the effect of linagliptin on insulin sensitivity in patients with well controlled T2DM and more studies involving larger number of patients and longer duration of follow up are needed to conclusively evaluate the effects of linagliptin in patients with well controlled T2DM. We also did not evaluate the presence or severity of nonalcoholic fatty liver disease (NAFLD) in our study subjects, and excluded patients with plasma aminotransferase elevations of more than 3 times upper limit of normal. There is a high prevalence of NAFLD in patients with T2DM [23] .It is well known that NAFLD is closely associated with insulin resistance and subjects with NAFLD have higher insulin resistance as compared to controls [24]. Even though we excluded patients with elevated aminotransferases, NAFLD can be present even in those with normal liver enzymes [25], and this could confound the results of our study. In addition, there was higher number of females in the linagliptin group (5 as compared to 2 in voglibose and placebo groups). Although some studies suggest that women are more insulin resistant as compared to males [26], recent evidence support the fact that women are more insulin sensitive [27, 28]. The higher proportion of females in linagliptin arm could also be a potential confounder in our study. Finally, we used

Table 3 Changes in biochemical parameters among the study groups

\begin{tabular}{|c|c|c|c|c|c|c|}
\hline Parameters & $\begin{array}{l}\text { Linagliptin group } \\
(n=10)\end{array}$ & $\begin{array}{l}\text { Voglibose group } \\
(n=9)\end{array}$ & $\begin{array}{l}\text { Control group } \\
(n=7)\end{array}$ & $\begin{array}{l}\text { P-Value Linagliptin } \\
\text { V/S Control }\end{array}$ & $\begin{array}{l}\text { P-Value Voglibose } \\
\text { V/S Control }\end{array}$ & $\begin{array}{l}\text { P-Value Voglibose } \\
\text { V/S Linagliptin }\end{array}$ \\
\hline$\Delta \mathrm{HbA1c}(\%)$ & $-0.2(-0.6$ to 0.3$)$ & $\begin{array}{l}-0.8 \\
(-0.9 \text { to }-0.1)\end{array}$ & $0.1(-0.1$ to 0.3$)$ & 0.422 & $0.038^{a}$ & 0.723 \\
\hline \multicolumn{7}{|l|}{ Mixed Meal Tolerance Test } \\
\hline$\triangle \mathrm{AUC}$ C-pep (nmol/L) & $\begin{array}{l}-100.5 \\
(-174.8 \text { to } 75.6)\end{array}$ & $\begin{array}{l}-80.3 \\
(-217.6 \text { to } 15.0)\end{array}$ & $\begin{array}{l}-24.9 \\
(-153.2184 .6)\end{array}$ & 0.669 & 0.470 & 0.780 \\
\hline$\Delta \mathrm{M}_{0} \times 10^{-8}(1 / \mathrm{min})$ & $1.5(0.2$ to 2.7$)$ & $3.5(-1.4$ to 3.9$)$ & $3.7(0.6$ to 6.7$)$ & 0.497 & 0.918 & 0.475 \\
\hline$\Delta \mathrm{M}_{1} \times 10^{-8}(1 / \mathrm{min})$ & $\begin{array}{l}-2.1 \\
(-3.7 \text { to } 0.2)\end{array}$ & $-3.3(-6.4$ to 2.1$)$ & $-3.8(-6.1$ to 0.6$)$ & 0.842 & 1.000 & 0.536 \\
\hline \multicolumn{7}{|c|}{ Hyperinsulinemic-Euglycemic Clamp Study } \\
\hline $\begin{array}{l}\triangle \text { Glucose disposal rate } \\
\text { (mg/Kg min) }\end{array}$ & $0.5(-0.2$ to 0.7$)$ & $0.2(0.1$ to 0.5$)$ & $0.1(-0.4$ to 0.4$)$ & 0.536 & 0.470 & 0.842 \\
\hline $\begin{array}{l}\text { Alnsulin sensitivity } \\
(\mathrm{mg} /(\mathrm{Kgmin}) / \mu U / \mathrm{mL})\end{array}$ & $0.6(-1.5$ to 1.3$)$ & $0.2(-0.9$ to 0.9$)$ & $0.2(-0.8$ to 0.7$)$ & 0.601 & 0.905 & 0.837 \\
\hline
\end{tabular}

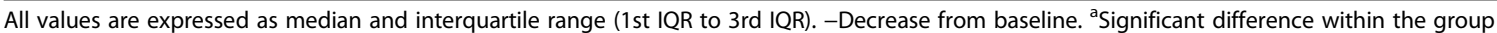
$\Delta A U C$ Area under curve, $\Delta M_{0}$ Basal $\beta$-cell function, $\Delta M_{1}$ postprandial $\beta$-cell function 
mixed meal test to evaluate pancreatic $\beta$-cell function and not the gold standard- hyperglycemic clamp study.

\section{Conclusion}

Linagliptin modestly improves glycemic profile in patients with well controlled T2DM; however, it may not have an effect on insulin sensitivity in these patients.

\section{Abbreviations}

AUC: Area under curve; DPP4: Dipeptidyl peptidase-4; FPG: Fasting plasma glucose; GLP1: Glucagon-like peptide-1; HbA1c: glycated hemoglobin; HEC: Hyperinsulinemic euglycemic clamp; HOMA-IR: Homeostatic model assessment of insulin resistance; HOMA- $\beta$ : Homeostatic model assessment of $\beta$ cell function; NAFLD: Nonalcoholic fatty liver disease; OD: Once a day; T2DM: Type 2 diabetes mellitus; TID: Three times a day

\section{Acknowledgements}

We acknowledge Ms. Harmanpreet Kaur for her unwavering support and technical assistance during the study. The authors also acknowledge Boehringer Ingelheim, India, for providing study medications.

\section{Availability of data and materials}

The datasets supporting the conclusions of this work are included in the article. On reasonable request, the content can be available from the corresponding author

\section{Authors' contributions}

Conceived and designed: $A B$. Patient's recruitment- GP, AB, RW. Collection and/or assembly of data- GP, SB. Data analysis and interpretation- GP, SB and $A B$. Data acquisition of clamp and insulin secretion model: AVK, KB. Manuscript writing- GP, SB. Manuscript editing: AB. All authors read and approved the final manuscript.

\section{Ethics approval and consent to participate}

The study was performed according to the declaration of Helsinki and was approved by the Institutional Ethics Committee of Postgraduate Institute of Medical Education and Research, Chandigarh, India. Written informed consent was obtained from all the patients to participate in the study.

\section{Consent for publication}

The authors confirm that they have obtained consent from the participants to publish the trial data.

\section{Competing interests}

The authors declare that they have no competing interests.

\section{Publisher's Note}

Springer Nature remains neutral with regard to jurisdictional claims in published maps and institutional affiliations.

\section{Author details}

Department of Endocrinology, Post Graduate Institute of Medical Education and Research, Sector- 12, Chandigarh PIN Code-160012, India. ${ }^{2}$ Department of Physiology, St. John's Medical College, Bangalore, India.

\section{Received: 8 April 2018 Accepted: 20 June 2018}

\section{Published online: 03 July 2018}

\section{References}

1. International Diabetes Federation. IDF diabetes atlas, 6th edn. Brussels. Belgium: International Diabetes Federation; 2013.

2. Drucker DJ, Sherman SI, Gorelick FS, Bergenstal RM, Sherwin RS, Buse JB. Incretin-based therapies for the treatment of type 2 diabetes: evaluation of the risks and benefits. Diabetes Care. 2010;33:428-33.

3. Deacon CF, Lebovitz HE. Comparative review of dipeptidyl peptidase-4 inhibitors and sulphonylureas. Diabetes Obes Metab. 2016;18:333-47.

4. Ahren B, Pacini G, Foley JE, Schweizer A. Improved meal-related beta-cell function and insulin sensitivity by the dipeptidyl peptidase-IV inhibitor vildagliptin in metformin-treated patients with type 2 diabetes over 1 year. Diabetes Care. 2005;28:1936-40.

5. Lyu X, Zhu X, Zhao B, Du L, Chen D, Wang C, et al. Effects of dipeptidyl peptidase-4 inhibitors on beta-cell function and insulin resistance in type 2 diabetes: meta-analysis of randomized controlled trials. Sci Rep. 2017:7:44865.

6. Nonaka K, Kakikawa T, Sato A, Okuyama K, Fujimoto G, Kato N, et al. Efficacy and safety of sitagliptin monotherapy in Japanese patients with type 2 diabetes. Diabetes Res Clin Pract. 2008;79:291-8.

7. van Genugten RE, van Raalte DH, Diamant M. Dipeptidyl peptidase-4 inhibitors and preservation of pancreatic islet-cell function: a critical appraisal of the evidence. Diabetes Obes Metab. 2012;14:101-11.

8. Lamers D, Famulla S, Wronkowitz N, Hartwig S, Lehr S, Ouwens DM, et al. Dipeptidyl peptidase 4 is a novel adipokine potentially linking obesity to the metabolic syndrome. Diabetes. 2011;60:1917-25.

9. Derosa G, Carbone A, Franzetti I, Querci F, Fogari E, Bianchi L, et al. Effects of a combination of sitagliptin plus metformin vs metformin monotherapy on glycemic control, beta-cell function and insulin resistance in type 2 diabetic patients. Diabetes Res Clin Pract. 2012;98:51-60.

10. Derosa G, Ragonesi PD, Carbone A, Fogari E, Bianchi L, Bonaventura A, et al. Vildagliptin added to metformin on beta-cell function after a euglycemic hyperinsulinemic and hyperglycemic clamp in type 2 diabetes patients. Diabetes Technol Ther. 2012;14:475-84.

11. Kern M, Kloting N, Niessen HG, Thomas L, Stiller D, Mark M, et al. Linagliptin improves insulin sensitivity and hepatic steatosis in diet-induced obesity. PLoS One. 2012;7:e38744.

12. Muniyappa R, Lee S, Chen H, Quon MJ. Current approaches for assessing insulin sensitivity and resistance in vivo: advantages, limitations, and appropriate usage. Am J Physiol Endocrinol Metab. 2008;294:E15-26.

13. DeFronzo RA, Tobin JD, Andres R. Glucose clamp technique: a method for quantifying insulin secretion and resistance. Am J Phys. 1979;237:E214-23.

14. Levy JC, Matthews DR, Hermans MP. Correct homeostasis model assessment (HOMA) evaluation uses the computer program. Diabetes Care. 1998;21:2191-2.

15. Matthews DR, Hosker JP, Rudenski AS, Naylor BA, Treacher DF, Turner RC. Homeostasis model assessment: insulin resistance and beta-cell function from fasting plasma glucose and insulin concentrations in man Diabetologia. 1985;28:412-9.

16. Hovorka R, Chassin L, Luzio SD, Playle R, Owens DR. Pancreatic beta-cell responsiveness during meal tolerance test: model assessment in normal subjects and subjects with newly diagnosed noninsulin-dependent diabetes mellitus. J Clin Endocrinol Metab. 1998:83:744-50.

17. Del Prato S, Barnett AH, Huisman H, Neubacher D, Woerle HJ, Dugi KA. Effect of linagliptin monotherapy on glycaemic control and markers of beta-cell function in patients with inadequately controlled type 2 diabetes: a randomized controlled trial. Diabetes Obes Metab. 2011;13:258-67.

18. Forst T, Uhlig-Laske B, Ring A, Graefe-Mody U, Friedrich C, Herbach K, et al. Linagliptin (BI 1356), a potent and selective DPP-4 inhibitor, is safe and efficacious in combination with metformin in patients with inadequately controlled type 2 diabetes. Diabet Med. 2010;27:1409-19.

19. Taskinen MR, Rosenstock J, Tamminen I, Kubiak R, Patel S, Dugi KA, et al. Safety and efficacy of linagliptin as add-on therapy to metformin in patients with type 2 diabetes: a randomized, double-blind, placebo-controlled study. Diabetes Obes Metab. 2011;13:65-74

20. Flory JH, Small DS, Cassano PA, Brillon DJ, Mushlin Al, Hennessy S. Comparative effectiveness of oral diabetes drug combinations in reducing glycosylated hemoglobin. J Comp Eff Res. 2014;3:29-39.

21. Retnakaran R, Qi Y, Opsteen C, Vivero E, Zinman B. Initial short-term intensive insulin therapy as a strategy for evaluating the preservation of beta-cell function with oral antidiabetic medications: a pilot study with sitagliptin. Diabetes Obes Metab. 2010;12:909-15.

22. Azuma K, Radikova Z, Mancino J, Toledo FG, Thomas E, Kangani C, et al. Measurements of islet function and glucose metabolism with the dipeptidyl peptidase 4 inhibitor vildagliptin in patients with type 2 diabetes. J Clin Endocrinol Metab. 2008;93:459-64.

23. Dai W, Ye L, Liu A, Wen SW, Deng J, Wu X, et al. Prevalence of nonalcoholic fatty liver disease in patients with type 2 diabetes mellitus: a meta-analysis. Medicine (Baltimore). 2017:96:e8179.

24. Fierbinteanu-Braticevici C, Negreanu L. Tarantino G. Is fatty liver always benign and should not consequently be treated? J Physiol Pharmacol. 2013;64:3-9. 
25. Portillo-Sanchez P, Bril F, Maximos M, Lomonaco R, Biernacki D, Orsak B, et al. High prevalence of nonalcoholic fatty liver disease in patients with type 2 diabetes mellitus and normal plasma aminotransferase levels. J Clin Endocrinol Metab. 2015;100:2231-8.

26. Mittendorfer B. Insulin resistance: sex matters. Curr Opin Clin Nutr Metab Care. 2005:8:367-72.

27. Karakelides H, Irving BA, Short KR, O'Brien P, Nair KS. Age, obesity, and sex effects on insulin sensitivity and skeletal muscle mitochondrial function. Diabetes. 2010;59:89-97.

28. Magkos F, Wang X, Mittendorfer B. Metabolic actions of insulin in men and women. Nutrition. 2010;26:686-93.

Ready to submit your research? Choose BMC and benefit from:

- fast, convenient online submission

- thorough peer review by experienced researchers in your field

- rapid publication on acceptance

- support for research data, including large and complex data types

- gold Open Access which fosters wider collaboration and increased citations

- maximum visibility for your research: over $100 \mathrm{M}$ website views per year 